\title{
Escenas de amistad femenina en Luzy sombra de Ana Roqué y Las memorias de Mamá Blanca de Teresa de la Parra: pensar y definir el yo en la intimidad ${ }^{1}$
}

\author{
Lucía STECHER y Natalia CISTERNA \\ Universidad de Chile \\ luciastecher@u.uchile.cl nataliacisterna@u.uchile.cl
}

\begin{abstract}
RESUMEN
Este artículo analiza las novelas Luz y sombra (1903) de Ana Roqué y Las memorias de Mamá Blanca (1929) de Teresa de la Parra, centrándose en las relaciones de amistad entre personajes femeninos. En estos textos la amistad entre mujeres es importante tanto en términos temáticos como estructurales. Por un lado, porque se constituye como una trama paralela o alternativa a la del amor romántico heterosexual y las presiones matrimoniales que sufren las mujeres, y, por otra parte, porque las novelas se construyen a partir de intercambios de cartas entre las amigas (Luz y sombra) o de creaciones artísticas colaborativas (Las memorias de Mamá Blanca). Proponemos que estas narrativas muestran la posibilidad de construir espacios y trayectorias alternativas para las mujeres, las que, en gran medida, dependen de la construcción de lazos de solidaridad e intimidad entre ellas. La escritura de cartas, la lectura en conjunto, el diálogo y la reflexión compartidas se constituyen en actividad centrales para la configuración de subjetividades femeninas menos sometidas a los roles y estereotipos de género.
\end{abstract}

Palabras clave: amistad femenina, intimidad, género epistolar, memorias, escritura de mujeres.

Scenes of feminine friendship in Luz y sombra Ana Roqué's and Las memorias de Mamá Blanca Teresa de la Parra's: I think and to define in the intimacy

\section{ABSTRACT}

This article analyses the novels Luz y sombra (1903) by Ana Roqué y Las memorias de Mamá Blanca (1929) by Teresa de la Parra, focusing on friendship between female characters. In these texts, friendships between women are important both in thematical as well as in structural terms. On the one hand, they constitute a parallel or alternative plot to

1 Este artículo se inscribe en el marco del proyecto de investigación FONDECYT Regular: No 1140745 “Constitución de autorías femeninas en el campo literario del Caribe Hispánico: 1830 a 1945" Investigadora responsable, Lucía Stecher y coinvestigadora, Natalia Cisterna. 
the one centered on heterosexual love and the pressure for women to marry. On the other hand, the novels are comprised of the letters exchanged by the protagonists (Luz y sombra) or built on the basis of collaborative artistic creations (Las memorias de Mamá Blanca). We propose that these narratives represent the possibility of building alternative spaces and trajectories for women, which depend largely upon building bonds of solidarity and intimacy. Writing letters, reading together, sharing dialogues and reflections play a main role in the configuration of female subjectivities that are less bound to gender roles and stereotypes.

Key words: female friendship, intimacy, epistolary, memoirs, women writing.

Sumario: 1.Amistad y matrimonio en Luz y sombra de Ana Roqué. 1.1. “...dejarte ver el estado de mi alma": el espacio intersubjetivo de las cartas. 1.2. Narrar el deseo femenino. 2. Escribir el "yo" a partir de la amistad en Las memorias de Mamá Blanca de Teresa de la Parra. 2.1. La amistad femenina como espacio de producción cultural. 2.2. Verse y construirse a través de la "otra".

La mujer era siempre para la otra mujer la rival en esencia o en potencia, puesto que ella sólo existía como correlativa del varón. Pero hoy cada mujer está llegando a ser para las otras, con exclusión de su papel en las relaciones entre los sexos, una hermana en sufrimiento, en propósito, en deber; un miembro de la humanidad con análogos problemas vitales (Camila Henríquez Ureña, "La mujer y la cultura", Obras completas, tomo 5).

Los ensayos, novelas, poemas y textos autobiográficos de mujeres del siglo XIX y principios del XX muestran muy claramente cuán central era para sus vidas el conseguir un "buen" matrimonio, es decir, una posición socio-económica estable y un estatus simbólico respetado. No casarse solía implicar un gran riesgo en términos de su seguridad económica -es por eso que la peruana Teresa González de Fanning reclama el derecho al trabajo sobre todo para las viudas y solteras- y un incómodo posicionamiento como "solterona". Este lugar central del matrimonio en el destino de las mujeres convertía a los varones de buena posición en codiciados candidatos, por los que se sentían obligadas a competir. El discurso del amor romántico, que jugó un rol tan importante en la configuración de subjetividades femeninas modernas y en la formación de lectoras y escritoras, contribuyó también a hacer del amor heterosexual y del matrimonio el único destino para el que se preparaba a las mujeres: "Para ella, el porvenir sólo presenta dos caminos practicables: el claustro que hoy día está ya casi abolido y el matrimonio. Para éste exclusivamente se la educa o por lo menos hacia ese norte se dirigen sus aspiraciones" (González de Fanning 1999: s/p).

En la variante más melodramática de la novela sentimental, que se empieza a escribir en la Europa dieciochesca y se masifica en el siglo XIX — con éxito también en Estados Unidos y la América hispánica- la centralidad del amor 
romántico, del mundo de los afectos y del destino matrimonial suele articularse en tramas predecibles y de fácil comprensión, desarrolladas por personajes que encarnaban valores antagónicos. Uno de los motivos más típicos de estos textos es el de la confrontación de dos mujeres por un hombre: una de las cuales representa al ángel del hogar - y suele ser rubia y de ojos azules - , mientras la rival encarna a la cortesana o mujer fatal $-\mathrm{y}$ es por lo general morena y de ojos negros. La moral conservadora de estos textos presenta desenlaces en los que la primera es premiada con el matrimonio y la segunda castigada con la muerte o el ostracismo social.

El peso del modelo femenino del "ángel del hogar"2, replicado en infinitas narrativas e impuesto a las mujeres a través de los más diversos soportes discursivos, ha sido reconocido por escritoras y críticas como especialmente paralizador para cualquier intento de legitimar posiciones autorales. Es conocida la frase de Virginia Woolf según la cual, "Killing the Angel of the House was part of the occupation of a woman writer" (cit. en Showalter 1972: 339). La crítica feminista ha destacado la importancia de las escrituras centradas en el "yo" femenino para subvertir ese mandato de abnegación vehiculizado por la figura del ángel del hogar (La Greca 2009). Desde esta perspectiva, escribir el yo, explorar distintas opciones de subjetivación, convertirse en sujetos de enunciación y de deseo, constituyen ejercicios fundamentales para enfrentar los discursos patriarcales que buscan aislar a las mujeres en el espacio de lo doméstico y en el rol único de madres y esposas.

En conjunto con la exploración en la propia subjetividad, los escritos de mujeres latinoamericanas decimonónicas y de las primeras décadas del siglo XX dan cuenta también de una creciente conciencia de la importancia de pensar las relaciones entre mujeres en términos distintos a los de la rivalidad y la competencia. Como destaca el epígrafe de este artículo, esta conciencia tiene que ver con la necesidad de constituir relaciones de solidaridad, que permitan superar el aislamiento y enfrentar en conjunto "análogos problemas vitales". Francine Massiello ha descrito como uno de los rasgos característicos de lo que denomina "novela femenina de vanguardia", la resistencia a la genealogía tradicional y a la autoridad patriarcal a través del establecimiento de vínculos horizontales, de amistad femenina:

Se refuerza esta independencia por medio de la posición de la protagonista con respecto a otros personajes, destacando otros circuitos de comunicación que favorecen la amistad entre mujeres: es decir, mujeres que leen juntas para aprovechar una lectura específica; mujeres que comparten fantasías y amplían su base intelectual; mujeres que se responsabilizan por una cultura netamente femenina (Massiello, 1985: 815).

${ }^{2}$ La frase "Ángel del hogar" proviene del título de un poema del escritor victoriano Coventry Patmore, en el que el sujeto lírico exalta las cualidades de sumisión, abnegación, pasividad, humildad y entrega de su esposa. 
La lectura de textos de escritoras caribeñas y latinoamericanas de principios del siglo XX muestra que, si bien el matrimonio y el amor siguen siendo temáticas de una importancia innegable en la vida de los personajes femeninos, sus historias también se articulan - y muchas veces se enuncian - en torno a la construcción de relaciones de complicidad y amistad con otras mujeres. Estas relaciones permiten la generación de espacios de intimidad, en los que las protagonistas tienen la posibilidad de distanciarse en alguna medida de los mandatos y modelos de femineidad que impone la sociedad patriarcal y generar lazos intersubjetivos que contribuyen a la configuración de un "yo" relacional, que explora en su interior a partir del encuentro con la mirada de la otra. La lectura en conjunto, la escritura e intercambio de cartas, el compartir manuscritos que narran la propia historia, se convierten en actividades fundamentales para la formación de estos vínculos entre mujeres, que ponen la solidaridad y la cooperación en el lugar que tradicionalmente ocupaban la rivalidad y competencia ${ }^{3}$.

Para este artículo hemos escogido dos novelas que nos permiten mostrar, en forma ejemplar, el rol que pueden tener las amistades femeninas en la estructuración de las tramas y en la configuración de situaciones de enunciación en las que la voz narrativa se articula con otra y la subjetividad se construye espejeándose en imágenes que le permiten identificarse y diferenciarse. Se trata de la novela Luz y sombra (1903) de la puertorriqueña Ana Roqué (1853-1933), quien además de escritora fue educadora, feminista y activa participante en el campo cultural de su país a través de la publicación de artículos periodísticos y de la fundación de revistas, y de Las Memorias de Mamá Blanca (1929) de la escritora venezolana Teresa de la Parra (1889-1936),cuya obra creativa e intelectual se centró, principalmente, en explorar y reflexionar sobre la mujer nueva y sus reales posibilidades de desarrollo en medio de las transformaciones modernas.

Nos pareció interesante analizar estas novelas en conjunto debido a que en ellas la amistad entre mujeres tiene un rol estructurante - en el caso del texto de Roqué por estar constituido en gran parte por cartas que intercambian las amigas y en el de De la Parra por el rol que tiene la amistad en la edición y publicación de las memorias de una de las protagonistas que configuran el cuerpo principal de la novela - y por lo significativas que resultan las diferencias que existen entre los personajes femeninos de las dos novelas, lo que permite pensar en cómo las escritoras reflexionaron y representaron las complicidades femeninas en distintas etapas vitales de las sujetos.

${ }^{3}$ Estas escenas se pueden encontrar en distintas obras del periodo, como por ejemplo las novelas Más arriba está el sol de Graziella Garbalosa, Ifigenia de Teresa de la Parra, Sueña Pilarín de Abigail Mejía y María Nadie de Marta Brunet, por mencionar solo algunas. 
Para una mujer burguesa del siglo XIX y principios del XX el fin de la infancia estaba marcado por el momento de la presentación en sociedad y el ingreso en el "mercado" matrimonial. Era difícil para una joven casadera sustraerse a las presiones sociales para que haga un "buen matrimonio". Es por eso que en las novelas con protagonistas que tienen entre quince y veinticinco años el noviazgo y el matrimonio son temas prácticamente ineludibles. Como veremos, al inicio de $L u z$ y sombra las amigas se encuentran precisamente en ese momento en que su principal preocupación es la de casarse pronto y bien. Por otra parte, Las memorias de Mamá Blanca pueden ubicarse por fuera del escenario matrimonial, porque la relación que permite la existencia pública del texto se construye entre una niña y una anciana. De esta manera, lo que nos interesa mostrar en este artículo son distintas estrategias de construcción de espacios relativamente alternativos a los previstos para las mujeres por la sociedad patriarcal, los que si bien siguen funcionando bajo su lógica y en no pocos momentos la reproducen, también permiten la emergencia de miradas más complejas y críticas, de cuestionamientos a los mandatos de género-sexual, de generación de alianzas femeninas que permiten superar el aislamiento y la reducción de la subjetividad a modelos estereotipados de feminidad.

\section{Amistad y matrimonio en Luz y sombra de Ana Roqué}

Es difícil leer la novela publicada por Ana Roqué en 1903 sin preguntarse a qué hace referencia su título, a qué podemos asociar la luz y la sombra que abren la historia narrada. Consideramos que estos elementos son significativos en tres niveles distintos, cuya comprensión da cuenta de una mayor complejidad en la propuesta narrativa de la que aparece en una lectura inicial. En primer lugar, pensamos que es posible leer la luz y la sombra asociadas a las dos amigas cuyas historias estructuran la trama: Matilde, la que realiza las elecciones "adecuadas", que la conducen a una vida feliz, correspondería a la luz, y Julia, que se casa por interés con un hombre mayor, al que no ama, sería la sombra. En segundo lugar, podemos entender los elementos del título en relación a la estructura de la novela: vista así, la luz se vincularía a la etapa de la infancia y juventud de las protagonistas, representada en el espacio del intercambio epistolar, mientras la vida de ambas como adultas, ya casadas y expuestas a los dolores de la vida tendría que ver con la segunda parte del título. Finalmente, estos elementos también aparecen vinculados a la reflexión en torno a la naturaleza humana y la igualdad de hombres y mujeres en términos de la coexistencia en ellos de elementos luminosos y oscuros. En este tercer nivel, la luz y la sombra son parte de cada ser humano y corresponden a lo que en los términos positivistas de la novela se describe como "fuerzas fisiológicas" las que claramente tienen que ver con el deseo sexual. En todas estas asociaciones la amistad entre Julia y Matilde tiene un rol fundamental: son sus cartas, sus diálogos, sus encuentros y apoyo mutuo los que sostienen el desarrollo de la trama y las propuestas ideológicas de la novela. Antes de analizar esta relación 
de amistad, nos gustaría profundizar un poco más en las distintas interpretaciones que le damos a los elementos que construyen el título de la novela.

La asociación de Matilde con la luz y de Julia con la sombra es probablemente la más inmediata y al final de cuentas también la menos interesante. Matilde y su vida modesta en el campo en un matrimonio humilde pero basado en el amor mutuo, representarían la luz, el modelo positivo que la conciencia autoral despliega ante sus lectores (y sobre todo lectoras). La sombra, por otro lado, estaría del lado de Julia, la amiga que vive en la ciudad y que opta por un matrimonio por conveniencia con un hombre mucho mayor. Aunque Julia reconoce directamente que no ama ni podrá amar a Sevastel, afirma que le es mucho más importante la posición social y la seguridad económica que él le ofrece. La narrativa muestra claramente que no hay ninguna opción de felicidad para una elección como la que hace Julia, fundada en la vanidad y el interés. En este nivel de lectura, Matilde ocupa el polo del ángel del hogar, mientras su amiga representaría el lugar de la cortesana o femme fatale. Los críticos que leen Luz y sombra como un texto fundamentalmente conservador, que incluso entra en contradicción con las opiniones y posicionamientos públicos de su autora, se detienen sobre todo en este nivel de la construcción de la trama y de los personajes femeninos (Chen Sham 1999). Como esperamos mostrar más adelante, si bien es cierto que existe una construcción en oposición e incluso dicotómica de los personajes femeninos, el vínculo de amistad entre ellas hace posible la deconstrucción de esta polaridad.

La luz y la sombra también se espejean en la estructura de la novela, la que está dividida en dos partes. La primera está configurada exclusivamente por las cartas que intercambian Matilde y Julia, compañeras íntimas de colegio que se han separado una vez terminada su educación formal. En la segunda parte predomina una voz narrativa extradiegética, focalizada a veces en Julia, otras en Matilde, y también en otros personajes. Se incluyen aquí otras dos cartas importantes cuya significación volveremos más adelante. En la sección epistolar de la novela las dos amigas han salido del colegio y se encuentran viviendo con sus padres, enfrentadas a su condición de mujeres "casaderas". Sin en ningún momento cuestionar el matrimonio como destino único e ineludible, las jóvenes ponderan en sus cartas los factores más importantes a considerar a la hora de decidirse por un marido. El rango de opciones es ciertamente estrecho, pero lo importante es la reflexión en torno a lo que se espera de la vida matrimonial. Los recuerdos escolares evocados en las cartas y el mismo presente de la escritura es todavía un momento luminoso en la vida de las protagonistas, y por lo tanto puede representar la luz de la primera parte del título. El segundo apartado, en el que la historia de las protagonistas es transmitida en forma mediada por un narrador, muestra una experiencia de vida mucho más dura y alejada de las expectativas que Julia y Matilde tenían del matrimonio. Julia se enamora poco antes de casarse de Rafael, un amigo de su futuro marido, pero pese a ello no se siente capaz de enfrentar el juicio social al que la expondría la ruptura de su noviazgo. Su vida de casada está marcada por la 
frustración, que la afecta tanto a nivel espiritual — porque no ama ni es amada por su marido-, como sexual. Este último aspecto, como veremos, es probablemente el más trasgresor del texto de Ana Roqué. Si bien Matilde es muy feliz en su matrimonio, viéndose recompensada por su honesta elección — también ella tenía la propuesta de un hombre mayor con mejor situación económica, pero renuncia al bienestar material por el amor que siente por su primo Paco-, tampoco su vida está del todo libre de sombras: en un primer momento son las que arroja sobre su felicidad el sufrimiento de su amiga Luisa, y más adelante la muerte de su primer hijo. Aunque en el desenlace la opción de Matilde y Paco es la que funda un proyecto de familia viable - nunca dejan de amarse, siguen trabajando honradamente y poco después tienen una niña-, toda la segunda parte del libro está marcada por penas y sufrimientos que las protagonistas no podían imaginar en su intercambio epistolar previo. De esta manera, la luz se asocia a un momento previo al matrimonio, a la escuela y a la amistad entre las niñas; la sombra, por su parte, se hace presente en la vida de adultas, en su realidad de mujeres casadas, en la etapa en que más presionadas están por los mandatos patriarcales.

La tercera forma en que aparecen la luz y la sombra en el texto está vinculada al desarrollo de la trama y a las reflexiones del narrador en torno a la naturaleza humana. De acuerdo a estas, la educación y la voluntad pueden contribuir a una conducta moral y conforme a las normas de la sociedad - las que no son criticadas abiertamente en el texto y muchas veces son defendidas-, pero no pueden nunca vencer del todo las fuerzas "fisiológicas" presentes tanto en hombres como en mujeres. En este sentido, luz y sombra conviven en todas las personas y lo que se necesita para que predomine la primera es que se reconozca a la segunda y se le proporcionen cauces adecuados de expresión. La sombra se asocia sobre todo a la sexualidad, la que puede desbordarse tanto en hombres como en mujeres si no hacen las elecciones adecuadas. Y estas son las que se orientan por el amor y por la posibilidad de que la relación entre el hombre y la mujer sea horizontal dentro de un esquema matrimonial que sigue siendo profundamente patriarcal.

El elemento común, que subyace a todas estas articulaciones de la relación entre "luz y sombra", es la amistad entre Julia y Matilde. Esta relación es estructurante en la primera parte de la novela, que como ya vimos se construye a partir de las cartas que intercambian las amigas. En la segunda parte, las cartas tienen una presencia textual mucho menor, pero la relación entre Julia y Matilde sigue siendo fundamental en el desarrollo de la trama y en la articulación de la propuesta ideológica de la novela.

\section{1 "...dejarte ver el estado de mi alma": el espacio intersubjetivo de las cartas}

En la última carta que le escribe Julia a Matilde, y que es una de las dos misivas que aparecen en la segunda parte de Luz y sombra, la primera le dice a su amiga: "Quizás ésta será la última vez que te comunique mis pensamientos... No sé si 
encontraré palabras para expresarte mis ideas, para dejarte ver una vez más el estado de mi alma" (Roqué 1994: 141). Al final de su escrito Julia, que se siente próxima a la muerte, le pide a su amiga que se haga cargo de su hija. Aunque la niña muere tres meses después - la veta naturalista-positivista de la novela atribuye su debilidad congénita a la herencia del sufrimiento moral de los padres - este gesto refuerza una vez más la profunda amistad y confianza que unen a Julia y Matilde.

En las palabras de Julia, las cartas son a la vez instancia de comunicación de pensamientos, de expresión de ideas, de revelación del estado del alma. Nos parece que esta escritura epistolar construye un espacio de intimidad alternativo, que posibilita cierta ampliación de horizontes para subjetividades femeninas enfrentadas a modelos y trayectorias muy restrictivas. Concordamos en este sentido con Nancy La Greca cuando destaca la importancia de la estructura epistolar de la novela para los procesos de subjetivación: "The exchange of letters lends itself to a reevaluation of feminine identity because of its intimate tone and the metafictional effect that reading the correspondence between the two women creates" (La Greca 2009: 155). La Greca explica que al difuminar los límites entre ficción y realidad y hacer partícipe y cómplice al lector de los pensamientos íntimos de las autoras de las cartas, las novelas epistolares contribuyen a reescribir la identidad femenina (2009: 155). Otro aspecto fundamental de la escritura de cartas, según esta crítica, es que permite a las mujeres narrarse a sí mismas: "In Roqué's novel women author their own lives and create their own symbolic selves. They are authors of their own identities" (La Greca 2009: 156).

Pese al estrecho margen de elección que tienen las amigas, la posibilidad de escucharse y de narrarse, les permite comprender mejor sus sentimientos, nombrar y ponderar sus temores y contraponer distintas perspectivas sobre la realidad. Las cartas dejan claro que la amistad entre ellas no se basa en su parecido, sino más bien en su diferencia, lo que hace posibles la confrontación y el diálogo entre diversas formas de pensarse como mujeres. Matilde admira el atrevimiento y audacia de Julia ("Tú eras la más revoltosa e incorregible del colegio, mientras que yo a nada me atrevía" Roqué 1994: 27-28), sin embargo es ella la que se opone a la decisión de sus padres de casarla con un hombre mayor que le puede dar una buena situación económica y la que defiende la importancia de sus deseos y sentimientos en la elección del marido. Julia, por el contrario, parece presa de su conformidad con las expectativas de la sociedad y con lo que se considera como el mejor destino para una mujer de su sector social. Esto no le impide ver el carácter frívolo y vacío de sus actividades, el que observa cuando le cuenta a Matilde cómo son sus días en la ciudad:

Después de un rato de frívola conversación, regresamos del paseo, y si es día de recibir, me quedo en casa para obsequiar a los amigos, y siempre pasamos un rato delicioso dando culto al arte. 
Pero no vayas a creer que es el arte que instruye, que eleva, que hace concebir hermosos ideales al que nosotros consagramos estas horas de solaz y de íntimas expansiones, no. Nosotros tomamos el arte como mero pasatiempo, como el mejor medio de soportar la monotonía de la vida: por eso cultivamos el arte que divierte, que habla a los sentidos y no al corazón.

Quédese aquél para los que saben sentir hondo y pensar algo, no para nosotros que no sabemos pensar ni sentir de ninguna manera: sólo procuramos distraer el fastidio de lo insustancial de nuestra manera de vivir (Roqué 1994: 42).

Esta cita presenta una denuncia de la nula función social de las mujeres de los sectores burgueses, a la vez que orienta al lector en cómo aproximarse a la novela: se trata de un texto que no aspira a entretener simplemente, sino que busca estimular la conexión de sus lectores con el pensamiento y el sentimiento. Las conversaciones entre Matilde y Julia destacan la importancia de tener un espacio - en este caso el epistolar - donde pensar con profundidad, donde confrontar una posición aparentemente más romántica (Matilde) con otra positivista y pragmática (Julia), donde poner bajo la lupa las exigencias de la sociedad, sobre todo en relación a los roles femeninos.

Es interesante cómo la imagen de Julia que va surgiendo a partir de las cartas contrasta profundamente con lo que su entorno social, y sobre todo su marido, perciben de ella. Aunque este personaje quiera en un primer momento describirse como fría y desapasionada, no tardamos en darnos cuenta - gracias a las perspectivas que nos ofrecen ella misma y Matilde - de que esta apariencia es falsa y superficial, que en el fondo es una mujer de sentimientos intensos. Julia es vista por su marido como una "estatua insensible e incapaz de experimentar ni pasiones ni deseos" (Roqué 1994: 105). Esta descripción hace recordar una novela puertorriqueña escrita por una mujer a la que Ana Roqué conoció y sin duda leyó: se trata de La Muñeca de Carmela Eulate Sanjurjo, de 1895, famosa en un primer momento por el prólogo que le escribiera Manuel Zeno Gandía y posteriormente por su irónica e inteligente mirada sobre el modelo de "mujer objeto", fomentado por los discursos hegemónicos, que al mismo tiempo lo critican por estimular la inutilidad, frivolidad y el derroche en las mujeres. Mientras Eulate Sanjurjo extrema el carácter de autómata de su protagonista, mostrando las implicancias de una construcción de lo femenino que celebra solo su belleza y elegancia, Ana Roqué evidencia tanto a través de la amistad de Julia con Matilde, como de la transformación de su personalidad cuando conoce a Rafael, que esa "muñeca" solo existe en el reino de las fantasías masculinas.

\subsection{Narrar el deseo femenino}

En términos narrativos, el rol estructurante de la amistad entre Julia y Matilde en Luz y Sombra se evidencia tanto a través de la centralidad que asume su correspondencia, como de los momentos de la trama en que las amigas se 
encuentran personalmente: cuando muere el hijo de Matilde, Julia aparece para acompañarla en su duelo, y cuando Julia cae enferma después de la muerte de su amado en el duelo con Sevastel, Matilde se traslada a San Juan para cuidarla. Es muy significativo que la única carta del texto con un destinatario distinto a una de las protagonistas, sea la que Matilde le escribe a su esposo desde la ciudad. En ella le cuenta con lujo de detalles lo que le ha pasado a Julia, incluyendo en su relato lo que le contara Sevastel de los hechos que el lector había conocido en el capítulo anterior (en el que se narra con detalle el duelo al que Sevastel reta a Rafael después de descubrir que ha mancillado su honor al pretender poseer a su esposa). De esta manera aparece, a través de Matilde, la perspectiva del marido de Julia, que repite y también complementa la información entregada por el narrador. Se contrapone en este capítulo la confianza y complicidad que muestra Matilde con su marido, con el mutuo desconocimiento que es la marca del matrimonio de su amiga. El modelo de un matrimonio horizontal, de personas de la misma edad, basado en un amor correspondido, se ve reforzado al ubicarlo en el nivel narrativo más importante y valioso del texto: el del intercambio epistolar.

En el momento de la crisis de Julia y de la visita de Matilde, el lector ya ha sido convencido de la altura moral y de la sensatez de esta última. Esto es importante para el rol que va a jugar ella en relación a la evaluación de la conducta de su amiga. Si bien, como dice Suárez Findley, Ana Roqué no pudo reconceptualizar las definiciones dominantes de lo que es un comportamiento femenino respetable (Suárez Findley 1999: 73) y organizó sus narrativas en torno a los valores de la domesticidad y la honra virginal, también es cierto que en Luz y sombra cuestiona fuertemente el discurso hegemónico que negaba el deseo sexual de las mujeres. En este sentido la autora se distancia en su novela del discurso de las feministas liberales puertorriqueñas que veían en las mujeres una fuerza moralizadora por su natural superioridad en lo que refiere al control de las pasiones y de la sexualidad. Ella misma fue una feminista liberal y es posible que en sus otras intervenciones defendiera esa perspectiva, pero en esta novela aboga más bien por la similitud entre hombres y mujeres en ese terreno, y denuncia la doble moral de una sociedad que le permite a los primeros vivir abierta y promiscuamente su sexualidad. En términos legales esta doble moral se manifiesta en que las mujeres adúlteras podían ser condenadas a una pena de hasta seis años de cárcel mientras las mismas conductas no eran penalizadas en los hombres (Suárez Findlay 1999: 27).

Como decíamos en el párrafo anterior, el hecho de que un personaje de una honorabilidad incuestionable como Matilde no juzgue negativamente a Julia por su conducta, es muy importante para lo que la conciencia autoral quiere establecer: que aunque se las eduque para suprimir sus deseos estos siempre terminan por expresarse: "Hay que convencerse de que la mujer no es un ángel; es un ser lleno de pasiones lo mismo que el hombre; y no basta a veces la buena educación moral que en teoría se les da, para preservarlas del desvarío que le imponen sus propias pasiones, su temperamento, su idiosincrasia natural" (Roqué 1994: 103). Este 
argumento se retoma y refuerza en la carta que Matilde le escribe a Paco, cuando le cuenta que frente a las palabras de Sevastel de que él pensaba que bastaba una buena educación moral para que la mujer se mantuviera lejos de las pasiones, ella replicó: "Eso sucedería... si la mujer fuera un ser distinto de los demás seres, y la educación pudiera sustraerla a las leyes propias de nuestra naturaleza imperfecta" (Roqué 1994: 122).

También es importante para la comprensión de la conducta de Julia la incorporación de la mirada médica, figura que como sabemos gozaba de la máxima autoridad en un contexto positivista. El médico que atiende a Julia se llama Bernard, al igual que el fundador de la medicina experimental, Claude Bernard, y a través de su diagnóstico y tratamiento queda claro que lo que le ocurre a Julia no es su responsabilidad, sino que debe ser visto como consecuencia de la falta de oportunidades que tuvieron sus pasiones para desarrollarse. La escena clave para explicar el desvío de su conducta moral y su enloquecimiento después de la muerte de Rafael es narrada por Julia en la última carta que le escribe a Matilde en la primera parte del libro:

Las caricias frías y convencionales de mi esposo me exasperaban, me enardecían: y cuando contemplaba aquel ser gastado, aquel joven viejo que se dormía cuando yo, pensando en otros ojos llenos de pasión y vida, me abrasaba, una desesperación sin nombre se apoderaba de mi ser, y después de dar vueltas en mi lecho solitario, y de despedazar a mordiscos los encajes de mis almohadas, o de mi rico pañuelo, una lluvia de lágrimas venía a refrescar mi cerebro, y por fin el sueño, sobreponiéndose a mi naturaleza exuberante de juventud, rendía mi materia, dejando a mi espíritu divagar por los soñados espacios de la dicha siempre vedada para mí. (Roqué 1994: $65)$.

Resulta sorprendente encontrar una cita como esta en una novela escrita en un contexto ideológico marcado por la preocupación por el atraso de Puerto Rico y por proyectos positivistas de "regeneración" nacional fuertemente orientados al control de la promiscuidad sexual y la mezcla racial (Findley Suárez 1999; La Greca 2009). Las propuestas de solución a los males del Puerto Rico finisecular y de principios de siglo XX tenían una dimensión fuertemente orientada a las mujeres, en su rol de formadoras de los futuros ciudadanos y de guardianas de la pureza racial y sexual de sus hogares. Este rol está asociado a la figura del ángel del hogar, que carece de un yo autónomo, de intereses y deseos propios, mucho menos de carácter sexual. La estrategia que utiliza Ana Roqué en Luz y sombra para subvertir esta configuración patriarcal de la feminidad y abrir un espacio de representación al deseo femenino está estrechamente vinculada a la ya mencionada centralidad de la amistad entre mujeres. El carácter intachable de Matilde —el que es más complejo de lo que parece a primera vista, pues aunque es esposa y madre ejemplar, también es una amiga incondicional y una joven que se atrevió a desafiar a su padre en la elección de marido - le da la autoridad moral que le permite explicar los "desvíos" en la 
conducta de Julia como producto de la represión y de la falta de expansión sexual al lado de su frío marido.

Es cierto que si bien el médico y Matilde exculpan a Julia del pecado de adulterio - su marido la descubre en compañía de Rafael antes de que la relación se consumara-, el desenlace de algún modo castiga a todos los miembros de la familia: Sevastel, Julia y la hija de ambos finalmente mueren por el impacto moral de lo vivido. Este final puede interpretarse como una defensa a ultranza de la institución matrimonial y una condena igualmente fuerte del adulterio (Chen Sham 1999), pero lo interesante es que a diferencia de lo que ocurría en el código penal, el castigo por un mal matrimonio y la falta de fidelidad recae sobre los dos miembros de la pareja, enfatizando así la crítica a los vínculos construidos sobre la base del interés material y la vanidad social.

Paralelamente al castigo al matrimonio construido sobre bases tan espurias, la novela presenta vínculos alternativos que son los que permitirían que la luz se imponga sobre la sombra: el ejemplo más evidente es el del matrimonio por amor entre Paco y Matilde, el que aun respetando los roles de género tradicionales destaca la importancia de un vínculo más horizontal entre los cónyuges. Pero el que nos ha interesado destacar acá y que consideramos que abre la posibilidad de leer la novela siguiendo coordenadas distintas a las tradicionales, es el de la amistad entre los personajes femeninos. Esta relación no se funda en ningún interés distinto al de la relación misma, es decir, se nutre de la afinidad y el afecto y se expresa a la vez que se consolida en el intercambio epistolar. La escritura de cartas sustrae a Matilde de su entorno doméstico tradicional y a Julia de su vida burguesa monótona y frívola; configura un espacio en el que pueden volverse reflexivamente sobre sí mismas y espejearse / diferenciarse en la imagen de la otra; al articularse en forma escrita, sus pensamientos, intuiciones y emociones pueden ser vistos con una distancia que abre la posibilidad de una revisión, reconsideración, desnaturalización. Es cierto que las subjetividades y expectativas afectivas y sociales de Matilde y Julia no son particularmente trasgresoras, pero creemos que la conciencia autoral propone sutilmente que es el vínculo entre ellas lo que permite subvertir modelos dicotómicos y restrictivos de femineidad e imaginar trayectorias distintas para las mujeres.

\section{Escribir el "yo" a partir de la amistad en Las memorias de Mamá Blanca de Teresa de la Parra}

\subsection{La amistad femenina como espacio de producción cultural}

Las imágenes de Julia y Matilde escribiendo y leyéndose mutuamente, se suman a una serie de escenas en la narrativa de autoras latinoamericanas y caribeñas de la primera mitad del siglo XX, en las que sus protagonistas, independiente de su condición social y situación emocional, siempre se las arreglan para disponer de un espacio en el que se puedan abandonar al libre fluir de los signos (Zanetti 2010: 
315-354; Cisterna 2015). Porque leer novelas, poemas o escribir largas cartas a las amigas o diarios personales, se presenta como un momento que permite cierto grado de independencia, un entretiempo propio, despojado de las estrictas normas familiares y de las obligaciones domésticas que se le imponen a su género sexual.

Lo íntimo en el marco del ejercicio letrado, adquiere ribetes particulares cuando se presenta como una instancia compartida entre mujeres, especialmente cuando la escritura se constituye en un medio para dar forma a la propia subjetividad en el seno de una amistad. Es precisamente esta especial manera de experimentar la actividad letrada en la intimidad femenina, lo que nos interesa analizar en la novela Las memorias de Mamá Blanca de Teresa de la Parra.

La novela de Teresa de la Parra se abre con un apartado titulado "Advertencia", el que se constituye como un contexto de enunciación ficcional que relata los últimos años de vida de la autora-personaje y explica las condiciones de producción de las memorias que leemos en los capítulos siguientes. Esta parte de la novela despliega una narración en primera persona desarrollada por una mujer, quien informa que lo que leeremos en el libro es parte de un manuscrito autobiográfico de una anciana llamada Mamá Blanca, que rememora su infancia en una hacienda venezolana en el siglo XIX. La narradora revela, además, que el manuscrito le fue legado cuando era niña por la anciana, con las siguientes palabras: "Ya sabes, esto es para ti. Dedicado a mis hijos y nietos, presiento que de heredarlo sonreirían con ternura diciendo: 'Cosas de Mamá Blanca', y ni siquiera lo hojearían. Escrito, pues, para ellos, te lo legaré a ti” (De la Parra 1997: 12).

En este apartado que abre el libro, la narradora entrega otra información de no menor relevancia: Ella ha intervenido el manuscrito original, por tanto, lo que leeremos son memorias que han pasado por un cuidadoso proceso de edición con el objetivo principal de ser publicadas.

La "Advertencia" es un capítulo que no fue inmediatamente comprendido por los críticos y editores de Las memorias de Mamá Blanca. Son escasos los análisis que se han detenido en esta parte del texto. Velia Bosch en su edición crítica de la novela menciona que en algunas versiones la "Advertencia" se suprimió o se puso al final del texto ${ }^{4}$. Estas variaciones dan cuenta de que el capítulo generó confusiones, tal vez debido a su aparente desconexión con el resto de la novela. ¿Qué relación podía tener este apartado, en donde se revelaban los mecanismos de configuración del texto, con la historia prístina de una infancia lejana que todos

${ }^{4}$ La investigadora señala al respecto, que en la edición mexicana de 1952 de editorial Pax-Mexico, se pone otro texto con el título de "Advertencia" que no fue escrito por la autora y en la versión holandesa de editorial Servire (s/f) la "Advertencia" se dispone al final de la novela. Ver las nota "b" a la "Advertencia" y la "Bibliografía comentada" de Teresa de la Parra. Las memorias de Mamá Blanca. Velia Bosch (Coord.) Editorial Universitaria. Santiago de Chile, 1997. 
quisieron ver cuando leyeron esta segunda novela de Teresa de la Parra? ${ }^{5} \mathrm{La}$ "Advertencia", a pesar de contarnos la amistad pueril entre una anciana y una niña, parecía obedecer a una naturaleza muy distinta a la del resto de la novela. La intención de describir un mundo infantil en el siglo XIX venezolano, quedaba suspendida en este apartado que conducía la mirada del lector hacia otro lugar: la trastienda de un proceso de creación y elaboración textual de carácter colectivo.

La "Advertencia" nos presenta una amistad poco usual entre una anciana de setenta años y una niña de menos de once. No hay entre ellas vínculo sanguíneo y tampoco amistades en común. La anciana, Mamá Blanca, y la niña, cuyo nombre nunca se menciona, simplemente se encuentran y forjan una relación fraternal basada fundamentalmente en la sintonía de caracteres o, en palabras de la narradora, en "misteriosas afinidades espirituales" (De la Parra 1997: 5). Como todo lazo afectivo, la amistad entre ambas se construye a partir de ciertas rutinas: cada tarde la pequeña recorrerá las calles del pueblo, cruzará el zaguán de la antigua casona y compartirá con la mujer largas charlas, recuerdos, lecciones de piano y pasteles preparados por la anfitriona.

En algún momento, durante estos encuentros, Mamá Blanca decide comunicarle a la niña que ella será la heredera del grueso cuaderno de hojas atadas con una cinta que contiene las memorias de su época de infancia, cuando compartía junto a sus pequeñas hermanas, juegos y travesuras en la hacienda familiar de Piedra Azul. La niña recién podrá reclamar el texto después de la muerte de Mamá Blanca, solicitud que por cierto no generará la más mínima resistencia de los hijos y nueras de la difunta. Tal como Mamá Blanca suponía, el escrito no despertó el menor interés en su familia. El hecho de que el cuaderno de memorias no haya sido entregado a la niña personalmente por la mujer, se debe a que ella seguía escribiendo los pliegos de papel hasta el final de sus días. En otras palabras, parte importante de esos recuerdos fueron reconstruidos en el periodo en el que tenían lugar los encuentros entre la anciana y la niña. La narradora recuerda precisamente la dedicación de la anciana a la elaboración de su texto en aquellos años en que la frecuentaba: "durante su vida y sus ratos perdidos, solía trabajar [en el manuscrito] clandestinamente, como el niño que juega con objetos destinados a más graves empleos" (De la Parra 1997: 11).

De lo anterior podemos deducir que al mismo tiempo que intentaba recuperar una infancia desdibujada en su memoria, Mamá Blanca iba interactuando con la niña, con la que hablaba y le contaba historias en su lenguaje, le aconsejaba, escuchaba y observaba:

\footnotetext{
${ }^{5}$ Esta novela de Teresa de la Parra fue leída por la crítica de su tiempo como una historia inocente, alejada de los temas complejos que había abordado con su primera incursión en el género, Ifigenia (1924), en donde la protagonista reclamaba por mayor libertad y cuestionaba el matrimonio como único destino del sujeto femenino.
} 
Me encontró parecidos con personas ya muertas, y como yo, por decir algo, le refiriese que en mi casa teníamos muchas rosas y el loro Sebastián, que sabía gritar los nombres de todo el mundo, me llevó para que conociese en detalle su patio y su corral, donde también había rosas (De la Parra 1997: 7).

Desde nuestro punto de vista, la niña no es solo una testigo privilegiada de los últimos años de Mamá Blanca y de su particular trabajo memorístico, es sobretodo un agente catalizador de ese pasado perdido de la anciana. En la púber espejea a los que se han ido, "personas ya muertas" y, con ello, un mundo que parecía irrecuperable. Pero también ve reflejada en ella algo de su propia vida, de esa niña que en un momento fue y que desapareció con las obligaciones de la adultez, del matrimonio y la maternidad. La menor significa para Mamá Blanca la posibilidad de recuperar una identidad y, asimismo, de configurar una conciencia propia de la infancia: modos de percibir y ordenar las experiencias, los seres y los objetos, y de relacionarse con ellos, que no responden al racionalismo instrumental del mundo adulto y que serán un claro anticipo del heterogéneo universo que conforman las infantes de Piedra Azul narrado por Mamá Blanca en sus memorias. En las palabras de la niña que refieren al loro de su casa y las flores del jardín, porque sí, sin ninguna razón de "importancia", es posible reconocer el lenguaje espontáneo y la cotidianidad doméstica de las pequeñas hermanas que pueblan las evocaciones de la anciana. En este marco, observamos una memoria escritural que si bien se constituye a partir de los recuerdos de Mamá Blanca, parece también requerir con una necesidad imperiosa de la presencia de la niña. Una interrogante que surge en este punto del análisis es precisamente cuánto de la pequeña, de su personalidad nómade y traviesa, están en el escrito de la mujer. La "Advertencia" abre una zona de ambigüedad con respecto a la definición de una autoría única, que se acentúa al enterarnos en la última parte del texto que la niña en la adultez actúo como editora del manuscrito:

Queriendo condensar y aspirando a corregir, he realizado una siega funesta. Como bandada de mariposas perseguidas, las frases originales han dejado sobre las viejas páginas sus pintadas alas: las alas de la vida. En el nuevo manuscrito son muy pocas las que vuelan todavía. Sin ejercer como yo la profesión de las letras, Mamá Blanca escribía con el gracioso abandono de esos autores cuyas hojas de libro corren ligeras sobre los años y nunca se marchitan. (De la Parra 1997: 12)

Como señalábamos anteriormente, las memorias nunca se concluyeron, eran más bien una serie de pliegos amarrados a una cinta que en su conjunto constituían un cuaderno, al que su autora sumaba hojas y hojas a medida que los recuerdos aparecían. Era una escritura en proceso, un flujo de momentos desplegados sin orden alguno que la niña, con los años y convertida en una mujer de letras, se 
encargará de organizar y publicar. Como todo proceso de edición que involucra recortes, la editora también se ve en la obligación de vincular los fragmentos y darle coherencia al corpus. En este sentido, se entiende que la narradora tuvo que completar aquellos espacios que surgieron de su "siega funesta". Si bien la narradora solo reconoce que debió reducir el texto y ordenarlo, esa confesión arrastra un segunda revelación implícita: para dar forma a la totalidad del escrito y que este no quedara como un conjunto de trozos dispersos tuvo que crear ahí, precisamente en el vació que ella provocó.

Estamos, entonces, frente a un texto que se configura a dos voces, la de Mamá Blanca y la de la editora. La base de las memorias son los recuerdos de la anciana, sin embargo, estos recuerdos son articulados en gran medida gracias a la presencia de la niña, la que opera en primera instancia como una fuente de inspiración, un estímulo a la adormecida memoria de la mujer. No obstante, sería un error pensar en la niña como una figura pasiva, un espejo inmóvil en el que Mamá Blanca proyecta las imágenes de su pasado. La niña es una creadora, una suerte de co-autora que intervendrá en el futuro los pliegos de papel y los reinventará en función de sus propios intereses intelectuales y estéticos. Teresa de la Parra en este breve capítulo introductorio desarrolla una compleja reflexión sobre los modos de creación desarrollados por mujeres. La autora instala una suerte de puesta en abismo en la que se puede observar una concepción de autoría que problematiza la imagen moderna del escritor aislado de la vida cotidiana, anclado solo en sus propias elucubraciones y exploraciones estéticas. Las memorias de Mamá Blanca desmitifica también la idea de que las tareas creativas solo pueden surgir en sujetos empoderados en los espacios de producción cultural. La visión burguesa, a fin de elevar al individuo como motor fundamental de la nueva sociedad, desconoce e invisibiliza las redes de cooperación y los múltiples diálogos que existen en toda labor artística. La novela de Teresa de la Parra pone al descubierto estos diálogos y reciprocidades que se construyen en el trabajo creativo, pero también va más allá: en la novela la escritura no solo deja de ser una actividad individual, sino que surge en una atmósfera de complicidades y diálogos fecundos entre mujeres. De este modo, la autora venezolana otorga al espacio compartido de intimidad femenina un potencial creador y de desarrollo reflexivo que rivaliza con la escena pública definida exclusivamente bajo coordenadas de empoderamiento masculino.

Al igual que en Luz y sombra de Ana Roqué, las dos protagonistas de Teresa de la Parra construyen un ámbito íntimo afectivo que les permite leer su mundo y sus vidas (el pasado en el caso de Mamá Blanca y el futuro en el de la niña) con una mayor libertad. Si en el ámbito público la anciana es una mujer inoperante, incapaz de entender los códigos de sociabilidad burguesa, y la niña por su corta edad no está habilitada para tener mayor protagonismo, en ese espacio de sororidad que las dos construyen parece no haber límites para pensar el pasado y un posible futuro, para ser sujetos que se reconocen y valoran recíprocamente $\mathrm{y}$, en definitiva, para elaborar relatos artísticos. 


\title{
2.2. Verse y construirse a partir de la "otra"
}

\begin{abstract}
No creo, por lo tanto exagerar al decir no sólo que la quería, sino que la amaba y que como en todo amor bien entendido, en su principio y en su fin, me buscaba a mí misma
\end{abstract}

(De la Parra 1997: 7)

Teresa de la Parra despliega un espacio en el que la reconstrucción de una historia personal femenina, y con ello de una identidad, pasa por la existencia de una "otra" en la que ver reflejada la propia individualidad. Al respecto, M. Bajtín al abordar el proceso de autoreflexión del sujeto con respecto a un "otro", plantea lo siguiente:

Cuando observo a un hombre íntegro, que se encuentra afuera y frente a mi persona, nuestros horizontes concretos y realmente vividos no coinciden. Cuando nos estamos mirando, dos mundos diferentes se reflejan en nuestras pupilas [...] Este excedente de visión que siempre existe con respecto a cualquier otra persona, este sobrante de conocimiento, de posesión, está determinado por la unicidad y la insustituibilidad de mi lugar en el mundo. (Bajtín 1995: 28-29; cursivas en el original)

El autor además sostiene que los actos individuales que permiten a un sujeto conocer a un "otro" completan a ese "otro" desde el excedente de visión que este último no tiene (Bajtín 1995: 29). En otros términos, el sujeto solo puede ser reconocido como una individualidad y, por tanto, existir, en la medida que un "otro" ratifique su existencia. Siguiendo esta línea de reflexión, en la novela de Teresa de la Parra observamos este mismo proceso de definición del sujeto a partir de la alteridad. Mamá Blanca recoge algo de ella en esa "otra", algo que no puede observar de manera directa. La niña es la que en definitiva termina completando la imagen de la mujer, en este caso de su historia pasada, que estaba velada a los propios ojos de la anciana por el paso de los años.

No es la primera vez que Teresa de la Parra recurre a una estrategia de configuración identitaria mediada por la presencia de otros y otras. En su primera novela, Ifigenia (1924), la escritora sitúa a su adolescente protagonista en un cruce de miradas con anónimos pasajeros de un hotel que le devolverán a la joven una imagen de sí distinta a la que ella tenía; posteriormente, un espejo situado en el hall del mismo lugar le entregará a través del reflejo del cristal el excedente de visión que le permitirá completar lo que desde su posición es incapaz de ver. Así, a través de la proyección de su figura la joven se transforma en una "otra" para sí misma, construyendo por primera vez una visión total de su persona.

$\mathrm{Ni}$ en Ifigenia ni en Las memorias de Mamá Blanca, el "otro", a partir del que la sujeto se define, está escogido al azar: incluso cuando son totales desconocidos, 
como en el caso mencionado arriba, siempre opera un proceso de selección. La sujeto elige verse en ciertos individuos y no en cualquier individuo. No todas las miradas le servirán para contruir su imagen. En las novelas de la escritora venezolana, las sujetos podrán no tener una visión completa de sus propias individualidades, pero eso no significa que no logren percibir, a veces de manera muy poco conciente y programada, un modelo de lo que aspiran llegar a ser. La identidad nunca es una suma de coincidencias, sino más bien el producto de una búsqueda que en definitiva, guiará la elección de ese "otro" en el que verse reflejada.

En Las memorias de Mamá Blanca, la anciana elige a la niña porque en ella ve desde el primer momento a la que buscó: "Siempre le pedí a Dios que entre los hijos me mandara siquiera una sola hijita. Como es terco y le gusta hacer milagros cuando no lo molestan, me la mandó ahora: a los setenta años" (De la Parra 1997: 8). La confesión de la anciana demuestra que la decisión de abrir las puertas de su casa a la infante que se asomaba por el umbral no fue casual. Pero, ¿cuáles son esas cualidades que ella ve en esta pequeña desconocida y que nunca pudo observar en sus hijos, nietos y nueras? La respuesta está, a nuestro modo de ver, en los rasgos que comparten ambos personajes. En efecto, hay aquí un proceso de reconocerse en "otra", conducido en principio por la mujer mayor, que necesariamente nos lleva a observar los elementos en común.

Teniendo en cuenta la distancia etaria que las separa, parecieran existir muy pocas coincidencias entre una mujer de setenta años y una niña de menos de diez. Sin embargo, ambos personajes comparten una misma sensibilidad que las hace valorar el trato fraternal y solidario con otras y otros, el no establecer jerarquías discriminadoras y el entablar relaciones libres de las imposiciones de su entorno social. Entre la niña que cruza distintos puntos de la localidad, que conecta en su errante paseo el afuera y el interior de la casa con singular libertad, y la anciana, cuyo hogar está siempre abierto a todos y todas, hay una misma forma de entender y situarse en el mundo, libre de los prejuicios sociales que marcan el espacio público: "Nadie comprendía que a mi edad se pudiesen pasar tan largos ratos en compañía de una señora que bien podía ser mi bisabuela. Como de costumbre, la gente juzgaba apoyándose en burdas apariencias" (De la Parra 1997: 7).

Es precisamente esta diferencia de edad la que posibilita la gran sintonía entre ambas. Las dos protagonistas de la "Advertencia" se encuentran en una etapa de sus vidas en las que el modelo de mujer doméstica y la obligación de constituir un matrimonio en los marcos de una sociedad burguesa, no son materia de preocupación. A diferencia de las protagonistas de Luz y sombra, ni la anciana ni la niña están sometidas a las exigencias de encontrar un pretendiente apropiado para formar una familia. Mientras Matilde y Julia están obligadas a ponderar y evaluar posibles candidatos a marido, por lo cual sus conversaciones están enfocadas en barajar las cualidades que debiera tener el pretendiente de turno, Mamá Blanca y la niña se desplazan con mayor libertad por distintos temas y están menos restringidas 
a configurar sus identidades bajo los discursos normativos de género. El episodio en el que la mujer mayor le plantea a la niña la necesidad de aprender y formarse en el arte de tocar el piano es revelador al respecto:

Estos dedos viejos no me ayudan ni me ayudaron nunca, porque en mi tiempo, hijita, no se usaba aprender con fundamento. Aprende, aprende tú para que gobiernes en las notas, no vengan ellas a gobernarte a ti. Óyelo bien y no lo olvides: este es el único mando que da ventajas y no deja remordimientos ni busca enemigos (De la Parra 1997: 11).

Hay en esta entusiasta apología por aprender piano una defensa apasionada de la necesidad de la mujer de instruirse. Mamá Blanca no aconseja a la pequeña sobre sus deberes en un hipotético futuro doméstico, sino por el contrario la conmina a "gobernar las notas" para que estas no la gobiernen a "ella", para lo cual debe estudiar. Así, si Mamá Blanca ve en la niña su pasado, la pequeña ve en la anciana su futuro, pero no el futuro de una mujer casada, con hijos y nietos, no el futuro de una apacible vida familiar, sino un futuro desconocido en el que ella podía ser protagonista

Para mis pocos años aquella larga existencia fraternal, en la cual se encerraban aventuras de viajes, guerras, tristezas, alegrías, prosperidades y decadencias, era como un museo impregnado de gracia melancólica, donde podía contemplar a mi sabor todas las divinas emociones que la vida, por previsión bondadosa, no había querido darme todavía [...] Yo no sabía aún que, a la inversa de los poderosos y los ricos de este mundo, la vida es espléndida no por lo que da, sino por lo que promete (De la Parra 1997: 7-8).

Es revelador que la niña escoja ver en la anciana aspectos contradictorios a los que en apariencia proyecta la reposada vida de la mujer en una antigua casona de aspecto colonial. La vieja casa y su dueña terminan constituyéndose para la menor en un portal que le permite visualizar un mundo marcado precisamente por códigos epistémicos muy distintos: el cambio, la sorpresa, los viajes; un mundo en donde lo dado no es lo importante, sino las infinitas oportunidades que ahí se ofrecen. La anciana parece indicarle con sus dedos, manchados por el paso de los años, no el pasado doméstico, sino un futuro moderno.

Sin embargo, la modernidad que Mamá Blanca sugiere no es la que representan sus hijos y sus nueras. Con ellos no pudo establecer el mismo vínculo que tiene con la niña. En el grupo familiar de la mujer se valora el rendimiento, el individualismo y el materialismo, como aspectos sustanciales del éxito y el reconocimiento social. Es por ello que las nueras, mujeres cosmopolitas y banales, desprecian la humildad de su suegra y prácticamente no se relacionan con ella. La narradora destaca que la unión que se establece al interior de ese grupo de mujeres es muy distinta a la naturaleza del vínculo que une a Mamá Blanca y la niña: "Las nueras de Mamá 
Blanca, muy unidas entre sí, gracias a la necesidad absoluta de vivir rivalizando" (De la Parra 1997: 9). Las nueras no constituyen una comunidad en la que primen el entendimiento y los lazos solidarios, sus personalidades se amoldan a las rivalidad que exhiben las mujeres burguesas en un mercado matrimonial competitivo donde la necesidad de conseguir un varón y conservarlo las lleva a observar a sus pares de género como una posible amenaza.

Ese mundo moderno, pragmático y exitista, en el que los varones y las mujeres se instalan en lo público compitiendo por el reconocimiento social (en el caso de los primeros) y por un marido (en el caso de las mujeres) es totalmente distinto al futuro abierto que traza Mamá Blanca a la niña, en el que la educación y la preparación son fundamentales. Esta visión con respecto a la instalación de la mujer en lo público es totalmente coincidente con el pensamiento de Teresa de la Parra. En su ensayo "Tres conferencias. Influencia de las mujeres en la formación del alma americana" (1930), la escritora defiende la educación femenina que le brinde a la mujer mejores oportunidades laborales, cuestionando a su vez el matrimonio como destino único del sujeto femenino. En definitiva, Las memorias de Mamá Blanca dialoga con otras reflexiones de Teresa de la Parra y, además, le entrega, a partir de los elementos que permite la ficción, la oportunidad de destacar esferas de convivencia y sororidad en las que las sujetos pueden soñar su futuro y revisar su historia con parámetros nuevos, libres del modelo del ángel del hogar.

En las novelas Luz y sombra de Ana Roqué y Las memorias de Mamá Blanca se despliegan espacios de comunión femenina en las que sus protagonistas se permiten pensar su identidad, las obligaciones de su género sexual y los procesos de creación desde perspectivas no necesariamente sujetas a las convenciones y mandatos sexogenéricos. Estamos frente a personajes femeninos que a través de la formación de lazos de sororidad, logran articular una esfera de intimidad que se rige por códigos dialógicos en los que prima la paridad y el trato horizontal. Si en el espacio público, organizado bajo lógicas patriarcales, la mujer se encuentra en una situación de dependencia, en este ámbito afectivo basado en la amistad las jerarquías se suprimen para dar paso a una comunidad en que la interacción permanente es vital. Manteniendo una eterna correspondencia o bien a través de diálogos y escritos que terminan dando lugar a memorias colectivas, los personajes de Roqué y De la Parra conservan y renuevan sus vínculos incluso a veces más allá de la muerte. La naturaleza de estos vínculos no se basa en relaciones familiares, no hay lazos sanguíneos que las obliguen a mantener el contacto, por el contrario, las relaciones afectivas se sostienen en afinidades espirituales o sintonías de caracteres construidas voluntariamente. En este sentido, un último aspecto a destacar es que aquí la amistad se constituye como una alegoría de una comunidad que decide libremente, sin imposiciones, a quién y cómo amar. Esto es especialmente notable en una época en la que las mujeres no tenían derecho a su autodeterminación. 


\section{BIBLIOGRAFÍA}

BAJTIN, Mijaíl.

1995 Estética de la creación verbal. México: Siglo XXI.

CHEN SAHM, Jorge.

1999 "Sanción moral y castigo: Contradicciones ideológicas en la narrativa de Ana Roqué", en La voz de la mujer en la literatura hispanoamericana de fin de siglo. San José: Editorial de la Universidad de Costa Rica.

CISTERNA, Natalia.

2015 "Ceremonias letradas: representaciones del campo cultural en la narrativa de autoras latinoamericanas y caribeñas de la primera mitad del siglo XX", Taller de letras [en prensa].

DE LA PARRA, Teresa.

1997 Las memorias de Mamá Blanca. 1929. Edición Crítica Velia Bosch (coord). Santiago de Chile: Editorial Universitaria.

1982 "Tres Conferencias. Influencia de las mujeres en la formación del alma americana", en Obras. Caracas: Biblioteca Ayacucho.

EULATE SANJURJO, Carmela.

1987 La muñeca. 1895. San Juan: La editorial, Universidad de Puerto Rico.

GONZÁLEZ DE FANNING, Teresa.

1999 "Trabajo para la mujer", en Graciela Batticuore, El Taller de la escritora. Veladas literarias de Juana Manuela Gorriti: Lima - Bs. Aires (1876-7 / 1892). Rosario: Beatriz Viterbo, pp. 287-292.

LA GRECA, Nancy.

2009 Rewriting Womanhood. Feminism, Subjectivity, and the Angel of the House in the Latin American Novel, 1887-1903. Pennsylvania: The Pennsylvania State University Press.

MASIELLO Francine,

1985 "Texto, ley, transgresión: especulación sobre la novela feminista de vanguardia", Revista Iberoamericana, vol. VI, $\mathrm{n}^{\circ}$ 132-133, juliodiciembre de 1985, pp. 804-22.

HENRÍQUEZ UREÑA, Camila.

2006 "La mujer y la cultura", en Obras y apuntes Tomo V. República Dominicana: Banreservas.

ROQUÉ, Ana.

1994 Luz y sombra. 1903. Rio Piedras: Universidad de Puerto Rico. 
SHOWALTER, Elaine.

1972 "Killing the Angel in the House: The Autonomy of Women Writers", The Antioch Review, vol. 32, no 3, 1972, pp. 339-353.

SUÁREZ FINDLAY, Eileen.

1999 Imposing Decency: The Politics of Sexuality and Race in Puerto Rico, 1870-1920. Durham: Duke University Press.

ZANETTI, Susana.

2002 La dorada garra de la lectura, lectoras y lectores de novela en América Latina. Rosario: Beatriz Viterbo. 